\title{
Endoplasmic Reticulum Stress Inhibition Protects against Excitotoxic Neuronal Injury in the Rat Brain
}

\author{
Anna-Leena Sokka, ${ }^{1 \star}$ Noora Putkonen, ${ }^{1 \star}$ Giuseppa Mudo, ${ }^{2}$ Evgeny Pryazhnikov, ${ }^{3}$ Sami Reijonen, ${ }^{1}$ Leonard Khiroug, ${ }^{3}$ \\ Natale Belluardo, ${ }^{2}$ Dan Lindholm, ${ }^{1,4,5^{\ddagger}}$ and Laura Korhonen ${ }^{1,5^{\ddagger}}$ \\ ${ }^{1}$ Minerva Medical Research Institute, Biomedicum Helsinki, FIN-00290 Helsinki, Finland, ${ }^{2}$ Department of Experimental Medicine, Division of Human \\ Physiology, University of Palermo, I-90134 Palermo, Italy, ${ }^{3}$ Neuroscience Center and ${ }^{4}$ Faculty of Biosciences, University of Helsinki, FIN-00014 Helsinki, \\ Finland, and ${ }^{5}$ Department of Neuroscience, Neurobiology, Biomedical Centre, S-75123 Uppsala, Sweden
}

Elevated brain glutamate with activation of neuronal glutamate receptors accompanies neurological disorders, such as epilepsy and brain trauma. However, the mechanisms by which excitotoxicity triggers neuronal injury are not fully understood. We have studied the glutamate receptor agonist kainic acid (KA) inducing seizures and excitotoxic cell death. KA caused the disintegration of the endoplasmic reticulum (ER) membrane in hippocampal neurons and ER stress with the activation of the ER proteins Bip, Chop, and caspase-12. Salubrinal, inhibiting eIF2 $\alpha$ (eukaryotic translation initiation factor 2 subunit $\alpha$ ) dephosphorylation, significantly reduced KA-induced ER stress and neuronal death in vivo and in vitro. KA-induced rise in intracellular calcium was not affected by Salubrinal. The results show that ER responses are essential parts of excitotoxicity mediated by glutamate receptor activation and that Salubrinal decreases neuronal death in vivo. Inhibition of ER stress by small molecular compounds may be beneficial for treatment of various neuronal injuries and brain disorders.

Key words: kainic acid; hippocampus; salubrinal; PERK; eIF2 $\alpha$; caspase-12

\section{Introduction}

Neuronal degeneration and dysfunction occur in many human neurological diseases leading to severe incapabilities and increased suffering of patients. The causes of cell loss in these disorders are not fully understood but involve both caspasedependent and -independent pathways (Leist and Jäättelä, 2001; Yuan et al., 2003). Cell death in neurons is controlled by the activity of signaling pathways and proteins with a cross talk between various organelles (Ferri and Kroemer, 2001). Mitochondria are crucially involved in cell death control and dysfunctions as shown also in many brain diseases (Lindholm et al., 2004). Recently, other organelles, such as the endoplasmic reticulum (ER), mediating cell stress responses have been linked to human diseases such as diabetes, Parkinson's disease, and amyotrophic lateral sclerosis (Wootz et al., 2004; Lindholm et al., 2006; Wu and Kaufman, 2006).

ER is an important cell organelle that is responsible among others for correct folding and sorting of proteins (Boyse and Yuan, 2006). ER functions can be disturbed by different insults

\footnotetext{
Received 0ct. 2, 2006; revised Nov. 27, 2006; accepted Dec. 15, 2006.

This work was supported by the Academy of Finland, the Sigrid Juselius Foundation, the Arvo and Lea Ylppo Foundation, Liv och Hälsa, the Magnus Ehrnrooth Foundation, the Maud Kuistila Foundation, Fondi di Ateneo at University of Palermo, Uppsala University, and the Minerva Foundation. A.-L.S. received a scholarship from von Frenckell's Foundation, and S.R. received a scholarship from the Finnish Medical Society (Finska Läkaresällskapet). We thank E. Lehto and J. Mäkelä for excellent technical assistance and T. Nyman and S. Laitinen for help with PCR.

${ }^{*}$ A.-L.S. and N.P. contributed equally to this work.

${ }^{\ddagger} D$.L. and L.K. contributed equally to this work.

Correspondence should be addressed to Dr. Laura Korhonen, Minerva Medical Research Institute, Biomedicum Helsinki, Haartmaninkatu 8, FIN-00290 Helsinki, Finland. E-mail: Laura.T.Korhonen@helsinki.fi. DOI:10.1523/JNEUROSCI.4289-06.2007

Copyright $\odot 2007$ Society for Neuroscience $\quad$ 0270-6474/07/270901-08\$15.00/0
}

such as accumulation of unfolded proteins and changes in calcium homeostasis (Verkhratsky, 2005; Boyse and Yuan, 2006). Disturbed ER functions induce expression of chaperones, attenuate protein translation, and activate ER-associated degradation (Bertolotti et al., 2000; Boyse and Yuan, 2006). This occurs by the activation of ER sensor proteins controlled by the chaperone Bip/ Grp78 (Bip), which is localized in the ER (Bertolotti et al., 2000). ER stress leads to activation of PRK (RNA-dependent protein kinase)-like ER protein kinase (PERK)/pancreatic eukaryotic translation initiation factor 2 subunit $\alpha$ (eIF2 $\alpha$ ) kinase, activating transcription factor-6 (ATF6), and the inositol-requiring enzyme 1 (IRE1), which in turn activate distinct signaling cascades mediating the ER stress response (Lee et al., 2002; Ma et al., 2002; Liu et al., 2003). ER stress has been widely studied for its role in the unfolded protein response (UPR), in cellular homeostasis and in calcium regulation (Verkhratsky, 2005; Boyse and Yuan, 2006). Apart from the UPR that is mainly adaptive and restorative in function, prolonged ER stress can trigger mitochondriadependent and -independent forms of cell death (Breckenbridge et al., 2003; Rao et al., 2004; Hetz et al., 2006). However, little is known about the role of ER responses in mediating pathophysiological reactions in acute brain injuries. Here we have studied excitotoxic brain injury induced by kainic acid (KA) and ER stress and its inhibition for neuroprotection against cell degeneration caused by glutamate receptor overstimulation occurring in different brain disorders.

\section{Materials and Methods \\ Animals}

Experiments were approved by the ethical committee and performed in accordance with the European Communities Council Directive (86/609/ 
EEC). Every attempt was made to reduce the number and to minimize pain and suffering of animals. Adult male Wistar rats (200-300 g; B\&K, Hull, UK) were given injections of KA (Calbiochem, Espoo, Finland) into the lateral ventricle $(0.35 \mu \mathrm{g} / \mu \mathrm{l})$ in a volume of $0.5 \mu \mathrm{l}$ per side, as described previously (Mudo et al., 1995), and killed at different time points from 3 to $48 \mathrm{~h}$. Controls received an equal volume of saline. Salubrinal (Sal; Calbiochem) was dissolved in dimethylsulfoxide (Sigma, Helsinki, Finland) and further diluted with saline. Rats were given injections of Sal 30 min before KA either intracerebroventricularly $(1 \mu \mathrm{l})$ using a $75 \mu \mathrm{M}$ solution or intraperitoneally $(0.1 \mathrm{ml})$ with $1 \mathrm{mg} / \mathrm{kg}$. Rats were decapitated in deep anesthesia, and brains were rapidly dissected, frozen in isopentane, cooled in liquid nitrogen, and stored at $-70^{\circ} \mathrm{C}$ until analysis. The right side of the brain was used for histology and the left for Western blot analyses.

\section{Neuronal cultures}

Hippocampal neurons prepared from embryonic day 17 rats (Harlan, Horst, The Netherlands) were cultured for $7 \mathrm{~d}$ on poly-ornithine (Sigma)-coated dishes in Neurobasal medium with B27 supplement (Invitrogen, Espoo, Finland) as described previously (Korhonen et al., 2001, 2003; Sokka et al., 2005). Different concentrations of KA (Calbiochem) or glutamate (Sigma) were added to the cells for various periods of time. In some experiments, $50 \mu \mathrm{M} \mathrm{Sal}, 1 \mathrm{~mm}$ kynurenic acid (Sigma), and 10 $\mu \mathrm{M}$ MK801 [(+)-5-methyl-10,11-dihydro-5H-dibenzo[a,d]cyclohepten5,10-imine maleate; Sigma] were added 30 min before KA. Concentrations of 50 and $20 \mu \mathrm{M}$ BAPTA-AM [1,2-bis(o-aminophenoxy) ethane- $N, N, N^{\prime}, N^{\prime}$-tetraacetic acid; Sigma] were added $2 \mathrm{~h}$ and $30 \mathrm{~min}$, respectively, before KA to lower increases in cell calcium (Zafra et al., 1991). Neuronal survival was determined by counting nuclei with fragmented/condensed nuclei using Hoescht blue (Sigma) or using staining with propidium iodine (Sigma), which is excluded from viable cells (Sundberg et al., 2006). In some experiments, we also used the MTT (Sigma) assay for cell viability (Korhonen et al., 2001, 2004).

\section{Western blotting}

Hippocampal tissue and neurons were lysed using ice-cold radioimmunoprecipitation assay buffer $(150 \mathrm{~mm} \mathrm{NaCl}, 1 \%$ Triton X-100, $0.5 \%$ sodium deoxycholate, $1 \%$ SDS, 50 mm Tris- $\mathrm{HCl}, \mathrm{pH}$ 8.0) supplemented with protease inhibitor mixture (Roche, Espoo, Finland). Equal amounts of protein were subjected to SDS-PAGE and blotted onto nitrocellulose filters (Amersham Biosciences, Helsinki, Finland). These were first incubated for $1 \mathrm{~h}$ in $50 \mathrm{~mm}$ Tris- $\mathrm{HCl}, \mathrm{pH}$ 7.5, $150 \mathrm{~mm} \mathrm{NaCl}, 0.1 \%$ Tween 20, and $5 \%$ skimmed milk and then overnight at $4{ }^{\circ} \mathrm{C}$ with primary antibodies: anti-Bip (1:1000; BD Biosciences, Helsinki, Finland); anti-Chop (1: 250; Santa Cruz Biotechnology, Heidelberg, Germany); anti-caspase-12 (1:2000; Chemicon, Helsinki, Finland); anti-phosphorylated (p)-PERK (1:500) and anti-PERK (1:500; both from Santa Cruz Biotechnology); anti-p-eIF2 (1:1000) and anti-eIF2 (1:1000; both from Cell Signaling, Espoo, Finland); and anti-actin (1:5000; Sigma). After washing, the filter was incubated with horseradish peroxidase-conjugated secondary antibodies (1:2500; Jackson ImmunoResearch, Espoo, Finland), followed by detection using enhanced chemiluminescence (Pierce, Helsinki, Finland). Quantification was performed using GelDoc (Bio-Rad, Espoo, Finland).

\section{Immunochemistry}

In vivo. Freshly frozen $10 \mu \mathrm{m}$ rat brain sections were cut on a cryostat, mounted onto Superfrost slides (Metzel-Gläser, Braunschweig, Germany), and fixed for $10 \mathrm{~min}$ at $-20^{\circ} \mathrm{C}$ using acetone-methanol (1:1). Slides were first incubated for $1 \mathrm{~h}$ with $5 \%$ bovine serum albumin (BSA: Sigma)/PBS/0.1\% Triton X-100 at room temperature and then overnight at $+4^{\circ} \mathrm{C}$ with anti-Bip (1:100), anti-Chop (1:100), anti-p-eIF2 $\alpha$ (1:200), anti-p-PERK (1:100), anti-active caspase-3 (1:200; Cell Signaling), anticaspase-12 (1:200), anti-ATF6 (1:100; Pierce), and anti-p-c-jun (1:200; Santa Cruz Biotechnology) antibodies. After washing with PBS/0.05\% Tween 20, secondary Cy3- or Cy2-conjugated anti-mouse antibody (1: 300; Jackson ImmunoResearch) was added for $1 \mathrm{~h}$, and the slides were washed and mounted using gel-mounting medium (Sigma). Controls without a primary antibody showed no staining.

In vitro. Neurons were fixed for 20 min using $4 \%$ paraformaldehyde,
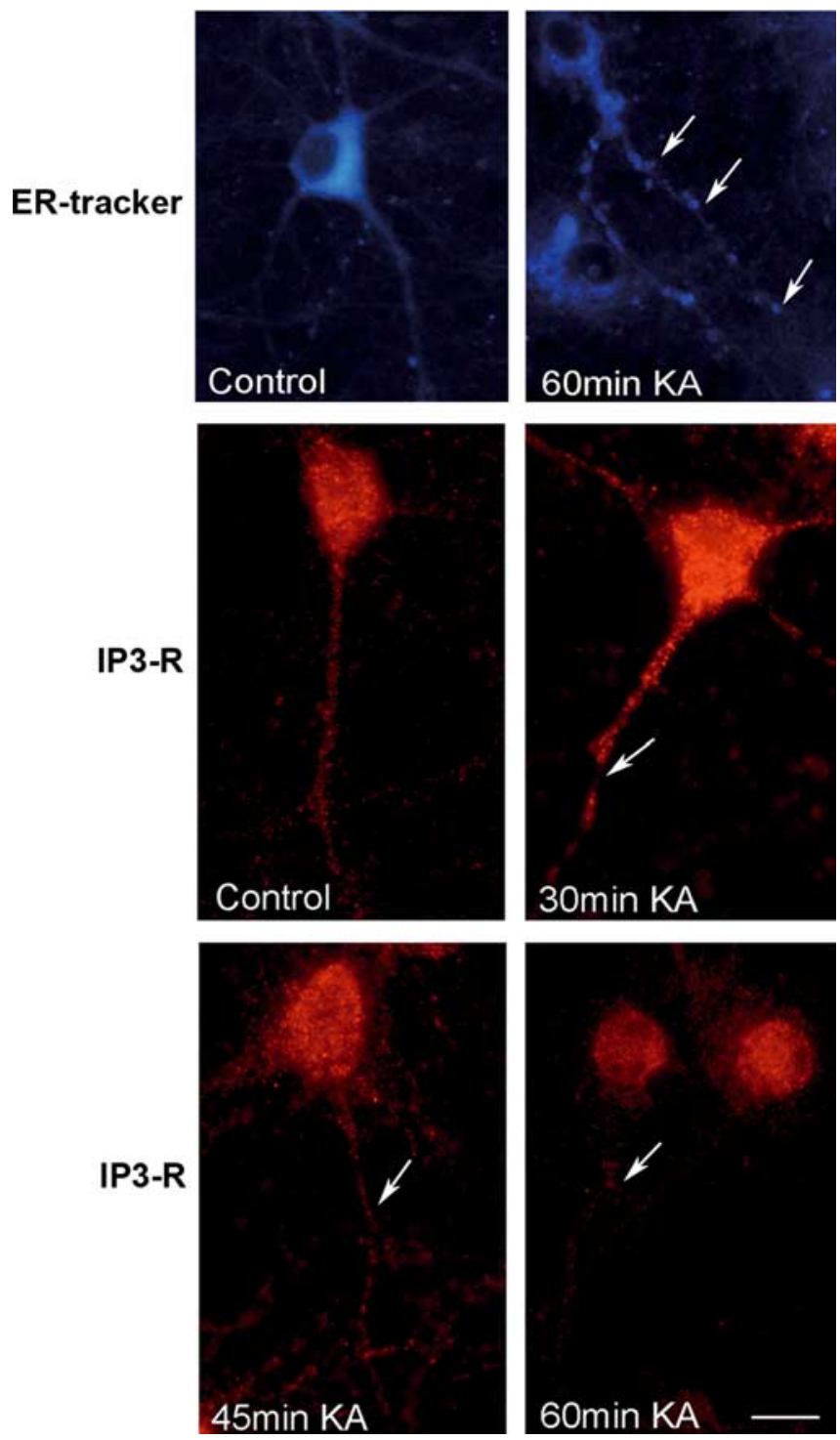

Figure 1. KA induces ER membrane changes in hippocampal neurons. A concentration of $100 \mu \mathrm{M}$ KA was added to the hippocampal neurons cultured as described in Materials and Methods. The integrity of ER was analyzed by the ER-tracker and by immunostaining for IP3-Rs. Arrows show disintegration of ER membranes 30 and 60 min after KA. Scale bar: top panels, 25 $\mu \mathrm{m}$; middle and bottom panels, $10 \mu \mathrm{m}$.

incubated for $1 \mathrm{~h}$ using 5\% BSA/0.1\% Triton X-100, and stained as above.

\section{Fluoro-Jade C and terminal deoxynucleotidyl transferase-} mediated biotinylated UTP nick end labeling staining

Frozen $10 \mu \mathrm{m}$ sections were immersed for $5 \mathrm{~min}$ in $1 \%$ sodium hydroxide $/ 80 \%$ ethanol, rinsed for $2 \mathrm{~min}$ in $70 \%$ ethanol, and then rinsed in distilled water. Potassium permanganate solution $(0.06 \%)$ was added for $10 \mathrm{~min}$, followed by a $10 \mathrm{~min}$ incubation in $0.0001 \%$ Fluoro-Jade C (Chemicon) (Korhonen et al., 2001; Schmued et al., 2005). After washing, the sections were air dried for $10 \mathrm{~min}$ at $50^{\circ} \mathrm{C}$, cleared in xylene, and mounted in dibutyl phthalate xylene (Sigma). Terminal deoxynucleotidyl transferase-mediated biotinylated UTP nick end labeling (TUNEL) staining (Roche) was done as described previously (Korhonen et al., $2001,2003)$. The number of Fluoro-Jade- and TUNEL-positive cells was counted at the same bregma level in control and treated rats $(n=4-8)$.

\section{Analysis of ER fragmentation}

Hippocampal neurons were loaded for 30 min with 100 nm Blue-white ER-tracker (Invitrogen, Espoo, Finland), and different concentrations of 
KA or glutamate were added for $60 \mathrm{~min}$ after changing the medium. Cells were observed under a fluorescent microscope (Leica, Espoo, Finland) using UV filters. To visualize ER membranes, cells were also stained using an anti-inositol-3-phosphate receptor (IP3-R) antibody (1:100; Chemicon).

\section{$\mathrm{Ca}^{2+}$ imaging}

Conventional wide-field fluorescence microscopy integrated in CellR Olympus (Tokyo, Japan) microscopy station was used to monitor $\mathrm{Ca}^{2+}$ transient responses. Dishes were pretreated with vehicle (1\% dimethylsulfoxide) or $50 \mu \mathrm{M}$ Sal for $30 \mathrm{~min}$ (short-term treatment) or for $20-24 \mathrm{~h}$ (long-term treatment). Cultures were washed and incubated for $40 \mathrm{~min}$ at room temperature with fura-2 AM dye ( $2 \mu \mathrm{M}$; Sigma). A concentration of $50 \mu \mathrm{M} \mathrm{KA}$ or $50 \mu \mathrm{M}$ glutamate was applied for $1 \mathrm{~min}$ through a bath perfusion system. $\mathrm{Ca}^{2+}$ transient responses were measured after background subtraction as the ratio between the fluorescence intensity at 340 and $380 \mathrm{~nm}$, respectively (Grynkiewicz et al., 1985). Plots were made using Microcal (Northampton, MA) Origin 6.0 software. Peak amplitude of $\mathrm{Ca}^{2+}$ responses was calculated as mean amplitude of the five time points after agonist application. Statistical differences were estimated using the $t$ test.

a
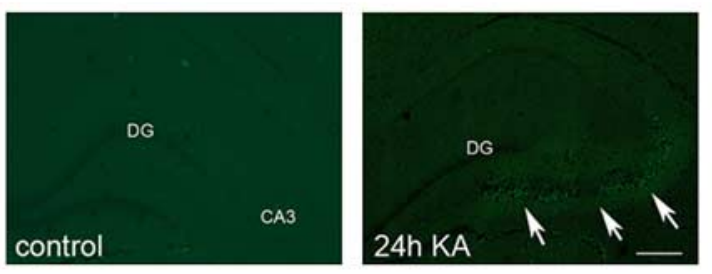

b
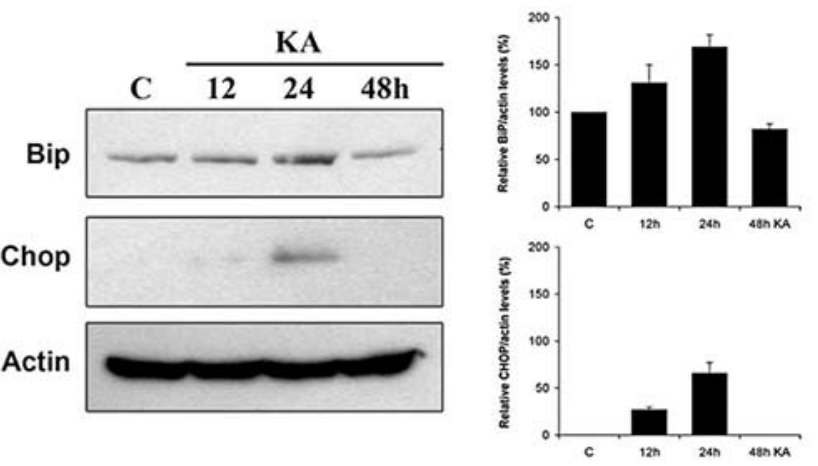

C

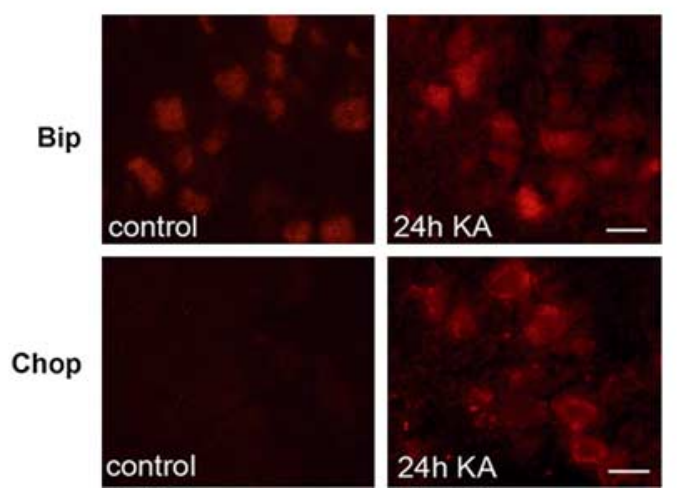

Quantitative PCR

RNA was prepared from hippocampal neurons and cDNA synthesized using $50 \mathrm{U}$ of SuperScript II reverse transcriptase and components given by the vendor (Invitrogen). Quantitative PCR was performed using LightCycler (Roche) and the following primers: BiP: forward $5^{\prime}-$ AAGGTGAACGACCCCTAACAAA-3', reverse 5' -GTCACTCGGAGAATACCATTAACATCT-3'; Chop: forward 5'-GCCTTTCGCCTTTGAGACAGT-3', reverse 5'-TGAGATATAGGTGCCCCCAATT-3'; activating transcription factor-4 (ATF4), forward 5'-CTACTAGGTACCGCCAGAAG-3' , reverse $5^{\prime}$-GCCTTACGGACCTCTTCTAT3'; $\beta$-actin: forward 5'-CACACTGTGCCCATCTATGA-3', reverse 5' CCATCTCTTGCTCGAAGTCT-3'. Amplification was performed using an initial 10 min step at $95^{\circ} \mathrm{C}$, followed by 50 cycles with $15 \mathrm{~s}$ at $95^{\circ} \mathrm{C}, 5 \mathrm{~s}$ at $60^{\circ} \mathrm{C}$, and $4-12 \mathrm{~s}$ at $72^{\circ} \mathrm{C}$, and with a final extension for $10 \mathrm{~min}$ at $72^{\circ} \mathrm{C}$. Specificity of the product was confirmed by melting-curve analysis. Quantification was done from data on the reaction kinetics, and expression levels were related to $\beta$-actin. To study splicing of $X B P$, reverse transcription-PCR and the following primers were used: forward $5^{\prime}$ AGAGTAGCAGCACAGACTGCGCG-3'; reverse 5' -GGAACTGG-GTCCTTCTGGGTA-3'.

\section{d}
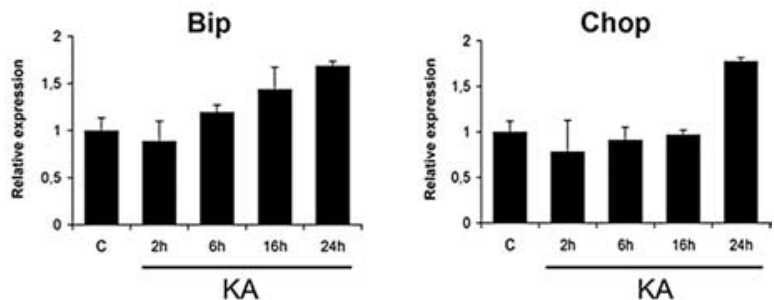

e
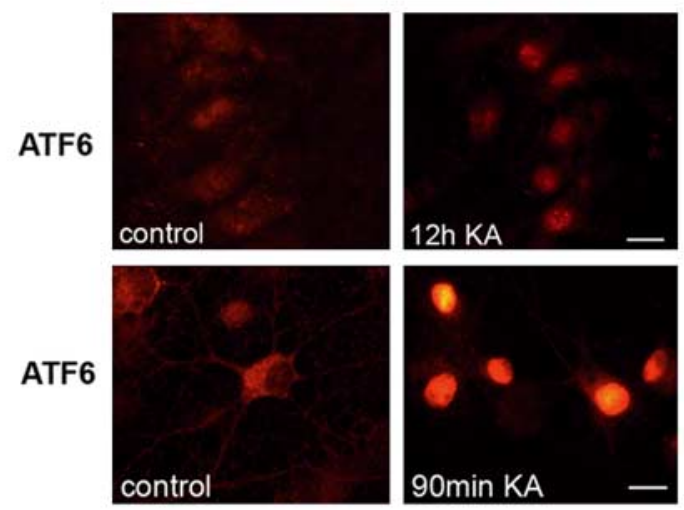

Figure 2. KA induces nerve cell death and ER stress in hippocampal neurons. $\boldsymbol{a}$, Sections were prepared from rat hippocampus after KA injections. Cell degeneration was analyzed by Fluoro-Jade C staining. Arrows show neuronal loss in the CA3 region at 24h. DG, Dentate gyrus. $\boldsymbol{b}$, Bip and Chop in hippocampus at different times after KA as detected by immunoblotting and specific antibodies. $\beta$-Actin was used as the control. $p<0.01$ for control versus $24 \mathrm{~h} \mathrm{KA}(n=3)$. c, Immunostaining of Bip and Chop in the hippocampal CA3 region after KA. $\boldsymbol{d}$, Bip and Chop mRNA levels in cultured neurons treated with $100 \mu \mathrm{m} \mathrm{KA}$ analyzed using quantitative PCR as described in Materials and Methods. Bip, $p<0.05$ for control versus $24 \mathrm{~h} \mathrm{KA}(n=5)$; Chop, $p<0.05$ control versus $24 \mathrm{~h} \mathrm{KA}(n=$ 5). $\boldsymbol{e}$, Immunostaining for ATF6 in the rat hippocampal CA3 area (top panels) and in cultured neurons (bottom panels). ATF6 is present in nuclei after KA. Scale bars: $\boldsymbol{a}, 500 \mu \mathrm{m} ; \boldsymbol{c}, \boldsymbol{d}, 25 \mu \mathrm{m}$. Error bars indicate SEM. C, Control. 
a

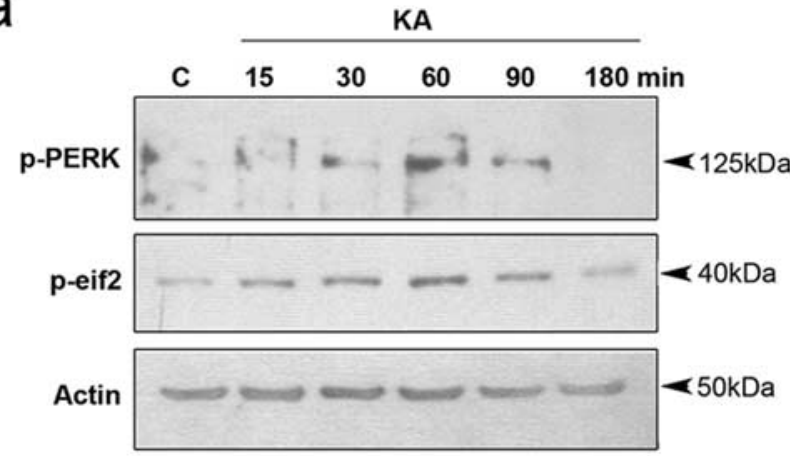

b

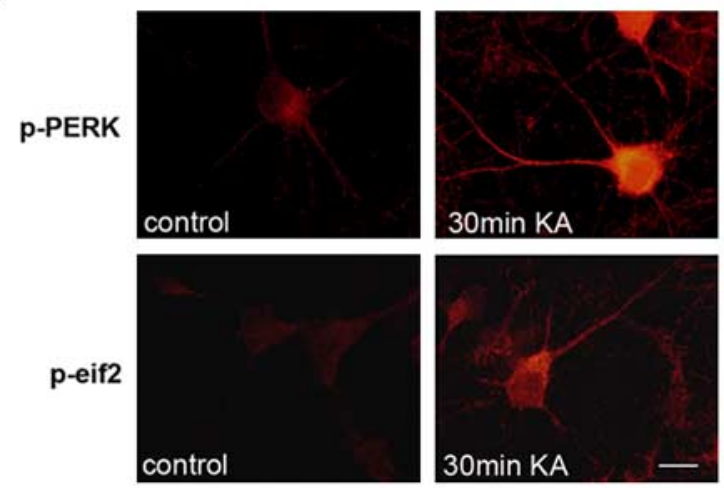

C
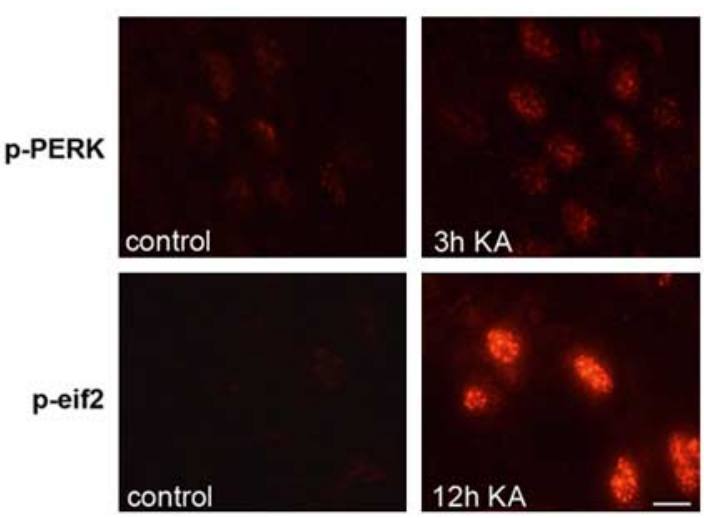

d

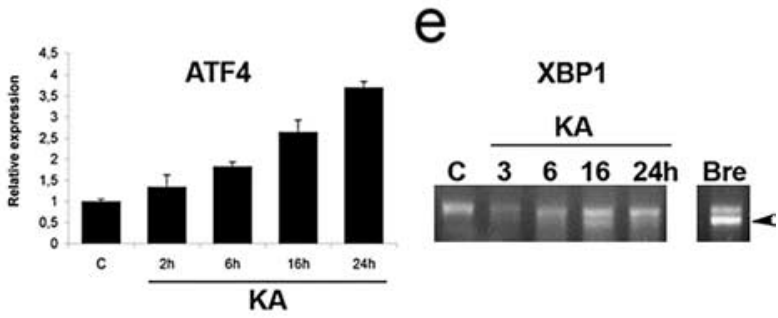

$f$

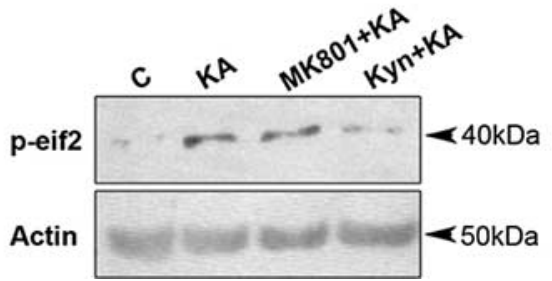

Figure 3. KA induces PERK and elF2 $\alpha$ phosphorylation in hippocampal neurons. $\boldsymbol{a}, \mathrm{p}$-PERK and $\mathrm{p}$-elF2 $\alpha$ was studied in hippocampal neurons treated with KA using immunoblotting and specific antibodies. $\boldsymbol{b}$, Immunostaining of p-PERK and p-eIF2 $\alpha$ in cultured neurons. Note the increased staining 30 min after KA. c, Immunostaining of p-elF2 $\alpha$ and p-PERK in CA3 in hippocampal neurons in vivo after KA.d, ATF4 mRNA levels in cultured neurons treated with $100 \mu \mathrm{m} \mathrm{KA}$ and analyzed by quantitative PCR. Note the increase in expression from $6 \mathrm{~h}$ onward. $p<0.01$ for control versus 16 and $24 \mathrm{~h} \mathrm{KA}(n=5)$. , Splicing accompanying XBP1 activation was analyzed in the neurons using reverse transcription-PCR. BrefeldinA (Bre; $0.5 \mu \mathrm{g} / \mathrm{ml}$ ) as a positive control induced XBP1 activation but not KA. $f$, Hippocampal neurons treated for $1.5 \mathrm{~h}$ with $100 \mu \mathrm{m}$ KA alone or in the presence of $10 \mu \mathrm{m}$ MK801 [(+)-5-methyl-10,11-dihydro-5H-dibenzo [a,d] cyclohepten-5,10-imine maleate] blocking NMDA receptors and $1 \mathrm{~mm}$ kynurenic acid (Kyn) inhibiting glutamate receptors. Scale bars: $\boldsymbol{b}, 25 \mu \mathrm{m} ; \boldsymbol{c}, 10 \mu \mathrm{m}$. Error bars indicate SEM. C, Control.

\section{Quantification and statistics}

Statistical comparisons were performed using one-way ANOVA, followed by Student's $t$ test. For each time point in vivo, four to eight rats were used, and the in vitro assays were repeated more than three times. $p \leq 0.05$ was considered significant.

\section{Results}

Activation of KA receptors induces ER responses in hippocampal neurons

To study the role of ER in excitotoxic neuronal response, we used hippocampal neurons that abundantly express KA glutamate receptors (Olney et al., 1974; Nadler et al., 1978). The addition of $100 \mu \mathrm{M}$ KA rapidly induced the fragmentation of the ER membrane shown by the ER-tracker dye and by staining with antibodies against IP3-R (Fig. 1). This concentration has been shown to induce a delayed degeneration of the neurons (Korhonen et al., 2001). To show that the neurons do not undergo a rapid necrotic response after KA, we studied lower concentrations of the compound $(25 \mu \mathrm{M})$ that also induced ER fragmentation (supplemental Fig. 1, available at www.jneurosci.org as supplemental material). Treatment of cells for $1 \mathrm{~h}$ using 25-200 $\mu \mathrm{M}$ KA did not cause any damage to the neuronal plasma membrane as shown by propidium iodine exclusion, in contrast to $300 \mu \mathrm{M}$ glutamate that did so to some extent (supplemental Fig. 1, available at www. jneurosci.org as supplemental material). These results showed that the ER fragmentation produced by KA is not secondary to necrosis that may follow excessive glutamate receptor activation.

We then studied whether KA also triggers ER stress as evident from alterations in ER stress proteins. As shown before, KA administration in vivo induces cell death particularly in the hippocampal CA3 region at $24 \mathrm{~h}$ (Fig. 2a) (Korhonen et al., 2001). The ER chaperone Bip was elevated in the hippocampus at $12 \mathrm{~h}$ with a maximum at $24 \mathrm{~h}$ (Fig. $2 b$ ). Similarly, the ER stressinducible leucine zipper-containing transcription factor Chop/ Gadd153 (Chop) was increased at $24 \mathrm{~h}$ after KA (Fig. 2b). Bipand Chop-positive cells increased particularly in CA3 neurons after KA, with an accumulation of Chop within neuronal nuclei (Fig. 2c). In KA-treated hippocampal neurons, Bip and Chop mRNA increased approximately twofold (Fig. 2d). ATF6 that controls the expression of ER sensors was also activated by KA, as shown both in vivo and in vitro (Fig. 2e).

\section{KA induces PERK and eIF2 $\alpha$ phosphorylation}

in hippocampal neurons

To study which other ER pathways are activated by KA in the neurons, we used antibodies against phosphorylated forms of PERK and its downstream target, eIF $2 \alpha$. A concentration of 100 $\mu \mathrm{M}$ KA within $30 \mathrm{~min}$ increased the levels of p-PERK and p-eIF $2 \alpha$ in the cultured neurons (Fig. $3 a, b$ ), whereas total levels of the 
proteins did not change (data not shown). An increased number of p-PERK- and p-eIF $2 \alpha$-immunoreactive CA3 neurons was also evident in vivo after KA (Fig. $3 c$ ). Increases in p-PERK and p-eIF $2 \alpha$ by $100 \mu \mathrm{M}$ KA were transient both in cultures (Fig. $3 a$ ) and in vivo (supplemental Fig. 2, available at www.jneurosci.org as supplemental material). Studies of the dose-response revealed that $25 \mu \mathrm{M}$ KA increased eIF $2 \alpha$ and Bip in the hippocampal neurons (supplemental Fig. 3, available at www.jneurosci.org as supplemental material). This was also observed using $75 \mu \mathrm{M}$ glutamate to stimulate the neurons (supplemental Fig. 3, available at www.jneurosci.org as supplemental material). Treatment with KA also induced the expression of ATF4 that is downstream of PERK (Fig. 3d). Splicing of XBP1 mRNA, activated via the IRE1 pathway did not occur significantly after KA (Fig. 3e), whereas increased p-c-Jun was readily observed (supplemental Fig. 2, available at www.jneurosci.org as supplemental material). Data showed that the effect of KA on p-eIF $2 \alpha$ was inhibited by kynurenic acid (Fig. 3f), blocking glutamate receptors (Zafra et al., 1991). These results demonstrate that KA through glutamate receptor activation induces ER stress with the activation of sensor proteins and downstream signaling in the hippocampal neurons.

KA increased cleavage of caspase-12 in hippocampal neurons Among cell-death proteins, caspase-12 resides in the ER membrane and can be cleaved by ER stress (Nakagawa et al., 2000; Nakagawa and Yuan, 2000). In rat hippocampus, caspase-12 was cleaved $12 \mathrm{~h}$ after KA (Fig. 4a), with the immunoreactivity present within neuronal nuclei in the CA3 region (Fig. $4 b$ ). In cultured neurons, the cleavage of caspase- 12 occurred rapidly after KA addition, showing the existence of a fast signal from the receptor (Fig. 4c). Incubation of the neurons in the presence of BAPTA-AM to chelate cell calcium (Zafra et al., 1991) decreased caspase-12 cleavage (Fig. $4 d$ ). This shows that elevation in calcium occurring after KA (see supplemental Fig. 4, available at www.jneurosci.org as supplemental material) and the stimulation of glutamate receptors causes caspase- 12 cleavage at the ER. Apart from calcium, KA is known to activate other signaling cascades downstream of the receptor (Lerma, 2003).

\section{Sal inhibits KA-induced neuronal death in vivo}

Sal is an inhibitor of eIF $2 \alpha$ dephosphorylation that was recently shown to counteract ER stress-induced cell degeneration in culture (Boyce et al., 2005). To study the effect of Sal on hippocampal neurons, we added Sal in combination with KA. Sal decreased the number of dying neurons with condensed nuclei by $\sim 70 \%$ (Fig. 5a) ( $p<0.01)$, as well as increased neuronal survival shown by the MTT assay (data not shown). Sal also reduced increases in Bip and the caspase-12 cleavage because of KA (Fig. 5b) and decreased the number of active caspase-3-positive neurons in KA-treated cultures (Fig. 5c). To study whether Sal may influence the calcium signal in neurons induced by KA, we measured increases in calcium in control and Sal-treated cells. As shown in experiments using fura-2, neither short-term nor long-term treatment with Sal affected the calcium elevation in neurons after stimulations by KA and glutamate (supplemental Fig. 4, available at www.jneurosci.org as supplemental material). This shows that Sal does not act upstream of ER in reducing calcium rise induced by KA treatments.

As in cultures, Sal administrated in vivo was able to protect against excitotoxic neuronal death in the hippocampus. Thus, the number of degenerating CA3 neurons was reduced by $75 \%$ in Sal-treated rats compared with controls after intracerebroventricular injections $(p<0.01 ; n=8)$ and by $60 \%$ after intraperi-
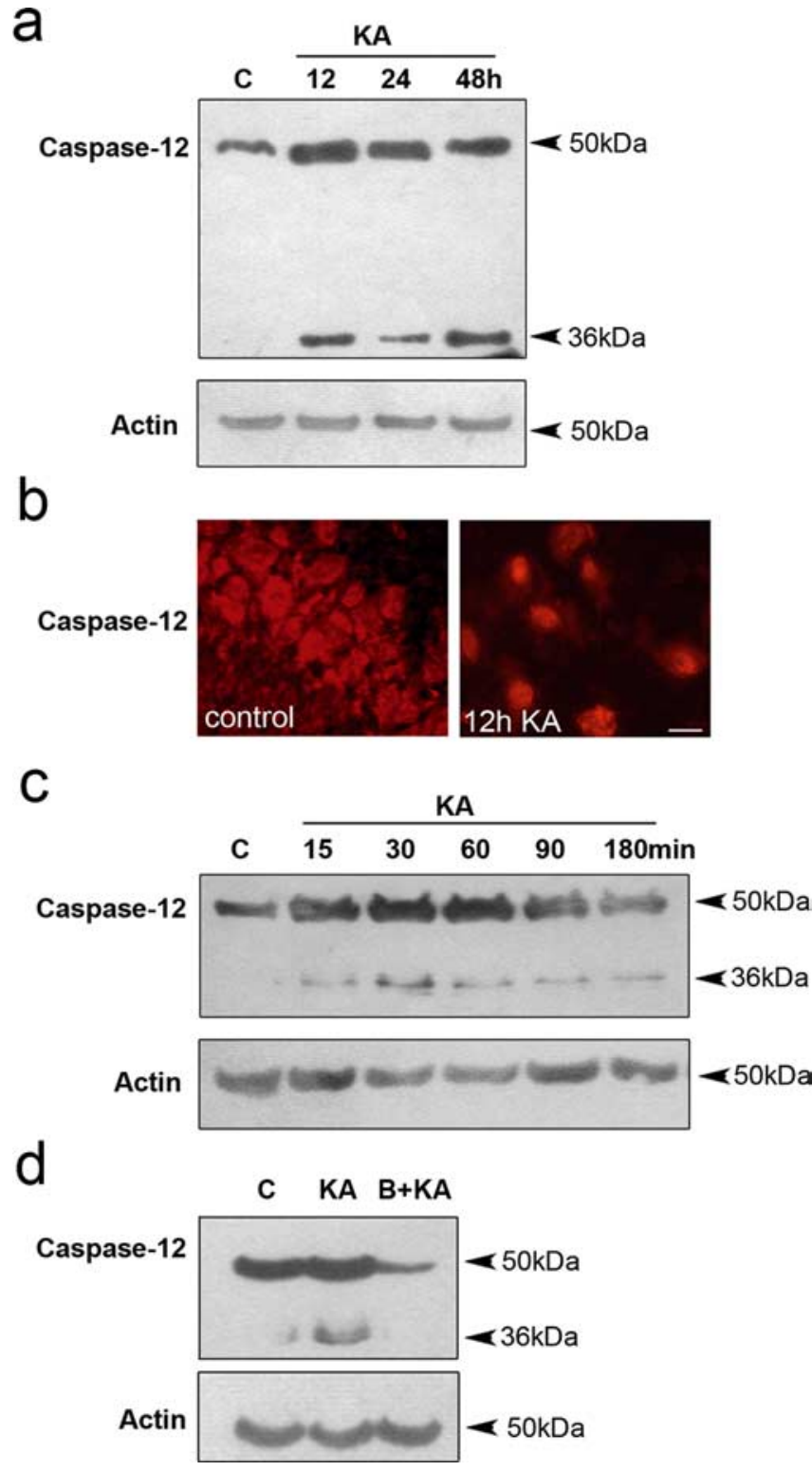

Figure 4. Cleavage of caspase-12 after KA in hippocampal neurons. $\boldsymbol{a}$, Caspase-12 in rat hippocampus at different times after KA injections as detected by immunoblotting. $\beta$-Actin was used as the control. $\boldsymbol{b}$, Immunostaining in CA3 neurons in vivo $12 \mathrm{~h}$ after KA showed nuclear localization of caspase-12. Scale bar, $25 \mu \mathrm{m}$. c, Caspase-12 in cultured hippocampal neurons was cleaved 15 min after $100 \mu \mathrm{m} \mathrm{KA.d}$, Lowering of intracellular calcium by $50 \mu \mathrm{M}$ BAPTA-AM inhibited the effect of $100 \mu \mathrm{m}$ KA on caspase-12. C, Control; B, BAPTA.

toneal injections of Sal (Fig. $5 d)(p<0.01 ; n=6)$. Sal also decreased by $\sim 70 \%$ the number of active caspase- 3 - and TUNEL-positive CA3 neurons in the rat hippocampus (Fig. $5 e$ ). The levels of p-eIF $2 \alpha$ were increased by Sal in the rat hippocampus, in line with eIF $2 \alpha$ as a target for its action (Fig. $5 f$ ). These results show that $S a l$ is able to penetrate into brain tissue in vivo and thereby affords significant neuroprotection against excitotoxic cell degeneration in brain.

\section{Discussion}

$\mathrm{KA}$ is known to activate non-NMDA glutamate receptors and trigger a delayed type of excitotoxic cell death in vulnerable brain regions, such as in the hippocampus and amygdala (Olney et al., 1974; Nadler et al., 1978; Korhonen et al., 2001). The mode of cell 
a
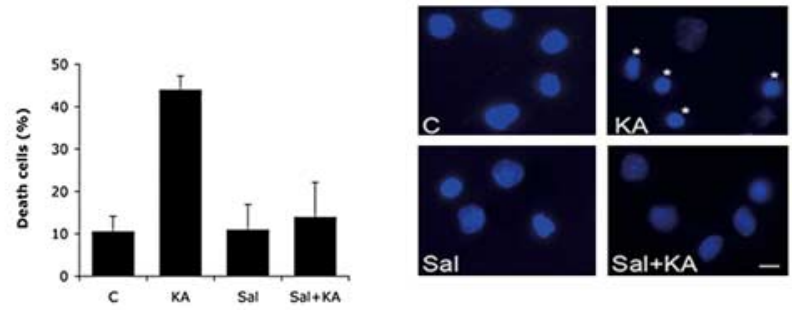

b

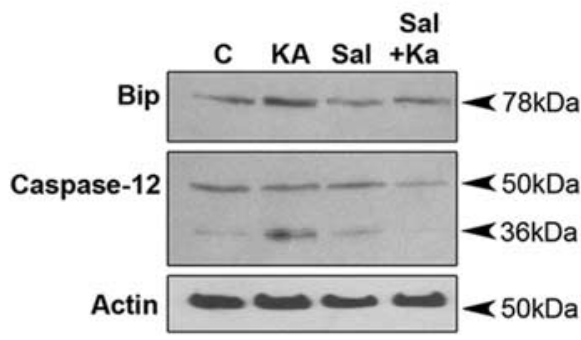

C

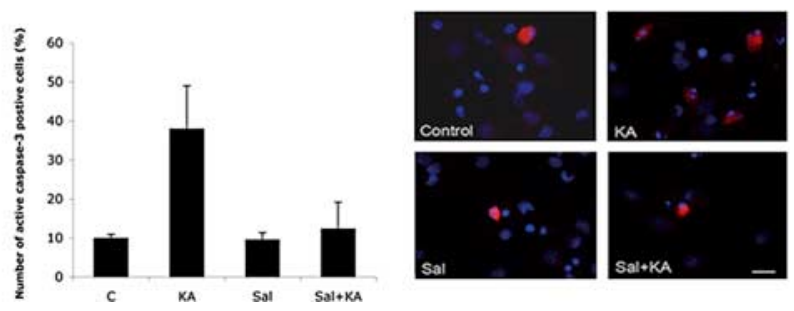

d
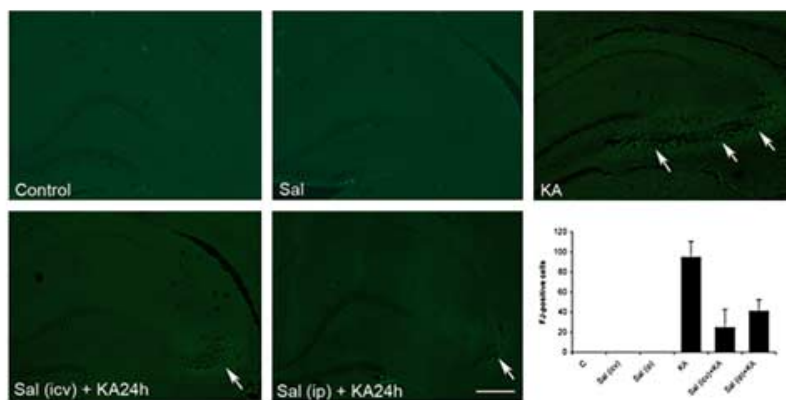

e
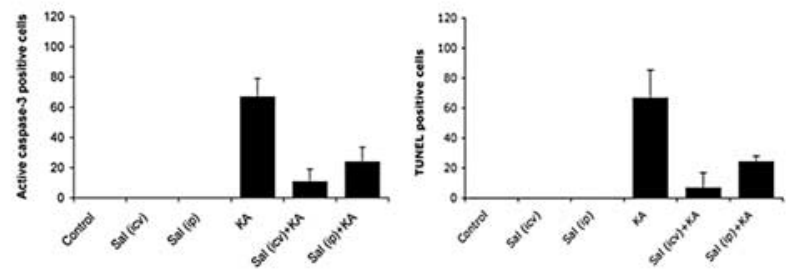

f
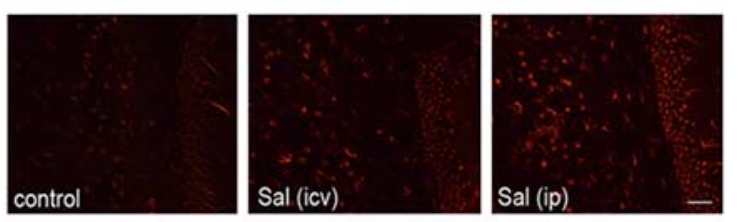

Figure 5. Sal inhibits KA-induced neuronal death in vivo. $a$, Number of degenerating hippocampal neurons in culture treated for $24 \mathrm{~h}$ with $100 \mu \mathrm{m}$ KA alone or in the presence of $50 \mu \mathrm{m}$ Sal. Insets show cells stained with Hoescht blue to reveal nuclear morphology. Sal protected against KA-induced cell death. $p<0.05 ; n=6 . \boldsymbol{b}$, Immunoblots of Bip and caspase-12 in cultured neurons treated with KA and Sal. Note the inhibition of caspase- 12 cleavage and reduced Bip in KA-treated cells by Sal. c, Immunostaining for active caspase-3 was done in control and $100 \mu \mathrm{m}$ KA and $50 \mu \mathrm{M}$ Sal-treated neurons. Insets show immunopositive neurons. $p<0.05$ for control versus KA and for Sal plus KA versus KA $(n=6)$. $\boldsymbol{d}$, Sal was injected intracerebroventricularly or intraperitoneally 30 min before KA. The number of degenerating neurons was assayed by Fluoro-Jade ( staining in the hippocampal CA3 region at $24 \mathrm{~h}$. Note the reduced cell degeneration by Sal treatments. $p<0.01$, control versus KA and for Sal plus KA versus KA $(n=6-8) . e$, Immunostaining for active caspase-3 and TUNEL in the CA3 region after KA and Sal treatments. $f$, Sal induces elF2 $\alpha$ phosphorylation in hippocampal CA3 neurons in vivo. Sal was given to rats $1 \mu$ of $75 \mu \mathrm{m}$ intracerebroventricularly or $1 \mathrm{mg} / \mathrm{kg}$ intraperitoneally, and the hippocampus was analyzed $24 \mathrm{~h}$ later. Scale bars: $\boldsymbol{a}, 25 \mu \mathrm{m}$; c, $50 \mu \mathrm{m} ; \boldsymbol{d}, 500 \mu \mathrm{m} ; \boldsymbol{f}, 150 \mu \mathrm{m}$. Error bars indicate SEM. C, Control.

death caused by KA includes activation of caspases as well as changes in expression of various pro- and anti-apoptotic molecules (Korhonen et al., 2001, 2003; Sokka et al., 2005). Members of the Bcl-2 and IAP (inhibitor of apoptosis protein) families have been shown to modulate the KA-mediated cell death (Lopez et al., 1999; Korhonen et al., 2003; Sokka et al., 2005). Caspase inhibitors can afford partial protection against KA-induced neuronal death, indicating that these enzymes are involved in excitotoxic injury (Kondratyev and Gale, 2000; Korhonen et al., 2001). However, the precise signals and pathways by which glutamate receptor activation triggers neuronal death have remained elusive.

In this study, we show that neuronal degeneration mediated by KA involves ER stress with the activation of ER sensors such as the PERK, ATF6, and IRE1 pathways. Preceding these, KA induced fragmentation of the ER membrane in neurons. Studies using specific blockers showed that the effects of KA on ER are attributable to activation of glutamate receptors. KA also induced cleavage of caspase-12 that occurred rapidly with the presence of the protein in neuronal nuclei. The translocation of caspase-12 into cell nuclei has been reported before in cultured myoblasts after ER stress and may be related to the ensuing cell death (Fujita et al., 2002). Activation of KA receptors is known to induce different signaling pathways and ion fluxes including elevation of calcium in neurons (Lerma, 2003). We observed that blocking calcium by BAPTA inhibited caspase- 12 cleavage, demonstrating that increased calcium can trigger the effect of KA on this ER caspase.

Previously, caspase-12 cleavage has been observed in hippocampal neurons lacking the calcium-binding protein hippocalcin (Korhonen et al., 2005). In addition, cells lacking caspase-12 are resistant against degeneration induced by the amyloid $\beta$ peptide and by tunicamycin causing ER stress (Nakagawa et al., 2000; Nakagawa and Yuan, 2000). The precise role of caspase-12 in ER stress-mediated cell death is not clear, however, because the human gene shows large deletions (Obeng and Boise, 2005). Data showed that Sal treatment also reduced caspase- 3 activation with an increase in neuronal viability. This shows that other caspases than caspase-12 are activated by KA and ER stress and contribute to the excitotoxic neuronal injury.

Apart from caspases, KA induced the transcription factor Chop in the hippocampal neurons. Chop has been linked to the 
ER stress-induced cell death and may act partly by inhibiting Bcl-2 (Urano et al., 2000; McCullough et al., 2001). ER stress can also, via the IRE1 kinase, activate the JNK pathway involved in cell-death control. Previously, JNK-3 was shown to be crucial for excitotoxic damage in the brain (Yang et al., 1997), and we also observed an increase in downstream p-c-Jun levels in KA-treated hippocampal neurons. It has also been shown that Grp78/Bip that suppress ER stress protects neurons against glutamateinduced excitotoxicity (Yu et al., 1999). It is likely that the different signals activated downstream of ER stress interact with and facilitate each other in inducing neuronal damage after KA treatment.

Small molecular compounds acting on intracellular pathways have emerged as promising cytoprotective agents with the capacity to inhibit cell death and restore function. Sal significantly reduced KA-induced neuronal degeneration both in cultured neurons and in hippocampal neurons in vivo. The effect of Sal was mediated via the inhibition of ER stress as shown by effects on caspase-12, caspase-3, and Bip. Previously, Sal was shown to inhibit dephosphorylation of eIF2 $\alpha$ and to counteract ER stress in cultured cells (Boyce et al., 2005). As shown by our data, the protective effect of Sal in vivo was robust, although not complete. This suggests that other pathways not blocked by Sal are also involved in neuronal death after the brain insult. It is known that ER responses interact with other cell organelles, including mitochondria. Dysregulated mitochondrial functions with disturbed calcium homeostasis have been considered to underlie excitotoxic and other brain injuries (Ankarcrona et al., 1995). The present results also demonstrate an unprecedented involvement of ER stress responses in excitotoxic neuronal damage induced by KA. The effect of on ER occurred rapidly and was related to an increase in calcium and the induction of different signaling pathways from the ER after KA. Data obtained with Sal showed that the inhibition of ER stress is also neuroprotective in vivo. Sal and other compounds preventing ER stress may therefore be of value in novel therapies for excitotoxic and other brain disorders.

\section{References}

Ankarcrona M, Dypbukt JM, Bonfoco E, Zhivotovsky B, Orrenius S, Lipton SA, Nicotera P (1995) Glutamate-induced neuronal death: a succession of necrosis or apoptosis depending on mitochondrial function. Neuron 15:961-973.

Bertolotti A, Zhan Y, Hendershot LM, Harding HP, Ron D (2000) Dynamic interaction of BiP and ER stress transducers in the unfolded-protein response. Nat Cell Biol 2:326-332.

Boyce M, Yuan J (2006) Cellular response to endoplasmic reticulum stress: a matter of life or death. Cell Death Differ 13:363-373.

Boyce M, Bryant KF, Jousse C, Long K, Harding HP, Scheuner D, Kaufman RJ, Ma D, Coen DM, Ron D, Yuan J (2005) A selective inhibitor of eIF2alpha dephosphorylation protects cells from ER stress. Science 307:935-939.

Breckenridge DG, Germain M, Mathai JP, Nguyen M, Shore GC (2003) Regulation of apoptosis by endoplasmic reticulum pathways. Oncogene 22:8608-8618.

Ferri KF, Kroemer G (2001) Organelle-specific initiation of cell death pathways. Nat Cell Biol 3:255-263.

Fujita E, Kouroku Y, Jimbo A, Isoai A, Maruyama K, Momoi T (2002) Caspase-12 processing and fragment translocation into nuclei of tunicamycin-treated cells. Cell Death Differ 9:1108-1114.

Grynkiewicz G, Poenie M, Tsien RY (1985) A new generation of $\mathrm{Ca}^{2+}$ indicators with greatly improved fluorescence properties. J Biol Chem 260:3440-3450.

Hetz C, Bernasconi P, Fisher J, Lee AH, Bassik MC, Antonsson B, Brandt GS, Iwakoshi NN, Schinzel A, Glimcher LH, Korsmeyer SJ (2006) Proapoptotic BAX and BAK modulate the unfolded protein response by a direct interaction with IRE1alpha. Science 312:572-576.

Kondratyev A, Gale K (2000) Intracerebral injection of caspase-3 inhibitor prevents neuronal apoptosis after kainic acid-evoked status epilepticus Brain Res Mol Brain Res 75:216-224.

Korhonen L, Belluardo N, Lindholm D (2001) Regulation of $\mathrm{X}$-chromosome-linked inhibitor of apoptosis protein in kainic acidinduced neuronal death in the rat hippocampus. Mol Cell Neurosci 17:364-372.

Korhonen L, Belluardo N, Mudo G, Lindholm D (2003) Increase in Bcl-2 phosphorylation and reduced levels of $\mathrm{BH} 3$-only Bcl-2 family proteins in kainic acid-mediated neuronal death in the rat brain. Eur J Neurosci 18:1121-1134.

Korhonen L, Näpänkangas U, Steen H, Chen Y, Martinez R, Lindholm D (2004) Differential regulation of X-chromosome-linked inhibitor of apoptosis protein (XIAP) and caspase-3 by NMDA in developing hippocampal neurons; involvement of the mitochondrial pathway in NMDA-mediated neuronal survival. Exp Cell Res 295:290-299.

Korhonen L, Hansson I, Kukkonen JP, Brännvall K, Kobayashi M, Takamatsu K, Lindholm D (2005) Hippocalcin protects against caspase-12induced and age-dependent neuronal degeneration. Mol Cell Neurosci 28:85-95.

Lee K, Tirasophon W, Shen X, Michalak M, Prywes R, Okada T, Yoshida H, Mori K, Kaufman RJ (2002) IRE1-mediated unconventional mRNA splicing and S2P-mediated ATF6 cleavage merge to regulate XBP1 in signaling the unfolded protein response. Genes Dev 16:452-466.

Leist M, Jäättelä M (2001) Four deaths and a funeral: from caspases to alternative mechanisms. Nat Rev Mol Cell Biol 2:589-598.

Lerma J (2003) Roles and rules of kainate receptors in synaptic transmission. Nat Rev Neurosci 4:481-495.

Lindholm D, Eriksson O, Korhonen L (2004) Mitochondrial proteins in neuronal degeneration. Biochem Biophys Res Commun 321:753-758.

Lindholm D, Wootz H, Korhonen L (2006) ER stress and neurodegenerative diseases. Cell Death Differ 13:385-392.

Liu CY, Xu Z, Kaufman RJ (2003) Structure and intermolecular interactions of the luminal dimerization domain of human IRE1alpha. J Biol Chem 278:17680-17687.

Lopez E, Pozas E, Rivera R, Ferrer I (1999) Bcl-2, Bax and Bcl-x expression following kainic acid administration at convulsant doses in the rat. Neuroscience 91:1461-1470.

Ma K, Vattem KM, Wek RC (2002) Dimerization and release of molecular chaperone inhibition facilitate activation of eukaryotic initiation factor-2 kinase in response to endoplasmic reticulum stress. J Biol Chem 277:18728-18735.

McCullough KD, Martindale JL, Klotz LO, Aw TY, Holbrook NJ (2001) Gadd153 sensitizes cells to endoplasmic reticulum stress by downregulating $\mathrm{Bcl} 2$ and perturbing the cellular redox state. Mol Cell Biol 21:1249-1259.

Mudo G, Salin T, Condorelli DF, Jiang XH, Dell'Albani P, Timmusk T, Metsis M, Funakoshi H, Belluardo N (1995) Seizures increase trkC mRNA expression in the dentate gyrus of rat hippocampus. Role of glutamate receptor activation. J Mol Neurosci 6:11-22.

Nadler JV, Perry BW, Cotman CW (1978) Intraventricular kainic acid preferentially destroys hippocampal pyramidal cells. Nature 271:676-677.

Nakagawa T, Yuan J (2000) Cross-talk between two cysteine protease families. Activation of caspase-12 by calpain in apoptosis. J Cell Biol 150:887-894.

Nakagawa T, Zhu H, Morishima N, Li E, Xu J, Yankner BA, Yuan J (2000) Caspase-12 mediates endoplasmic-reticulum-specific apoptosis and cytotoxicity by amyloid-beta. Nature 403:98-103.

Obeng EA, Boise LH (2005) Caspase-12 and caspase-4 are not required for caspase-dependent endoplasmic reticulum stress-induced apoptosis. J Biol Chem 280:29578-29587.

Olney JW, Rhee V, Ho OL (1974) Kainic acid: a powerful neurotoxic analogue of glutamate. Brain Res 77:507-512.

Rao RV, Ellerby HM, Bredesen DE (2004) Coupling endoplasmic reticulum stress to the cell death program. Cell Death Differ 11:372-380.

Schmued LC, Stowers CC, Scallet AC, Xu L (2005) Fluoro-Jade C results in ultra high resolution and contrast laeling of degenerating neurons. Brain Res 1035:24-31.

Sokka AL, Mudo G, Aaltonen J, Belluardo N, Lindholm D, Korhonen L (2005) Bruce/apollon promotes hippocampal neuron survival and is downregulated by kainic acid. Biochem Biophys Res Commun 338:729-735

Sundberg M, Savola S, Hienola A, Korhonen L, Lindholm D (2006) Glu- 
cocorticoid hormones decrease proliferation of embryonic neural stem cells through ubiquitin-mediated degradation of cyclin D1. J Neurosci 26:5402-5410.

Urano F, Wang X, Bertolotti A, Zhang Y, Chung P, Harding HP, Ron D (2000) Coupling of stress in the ER to activation of JNK protein kinases by transmembrane protein kinase IRE1. Science 287:664-666.

Verkhratsky A (2005) Physiology and pathophysiology of the calcium store in the endoplasmic reticulum of neurons. Physiol Rev 85:201-279.

Wootz H, Hansson I, Korhonen L, Näpänkangas U, Lindholm D (2004) Caspase-12 cleavage and increased oxidative stress during motoneuron degeneration in transgenic mouse model of ALS. Biochem Biophys Res Commun 322:281-326.

Wu J, Kaufman RJ (2006) From acute ER stress to physiological roles of the unfolded protein response. Cell Death Differ 13:374-384.
Yang DD, Kuan CY, Whitmarsh AJ, Rincon M, Zheng TS, Davis RJ, Rakic P, Flavell RA (1997) Absence of excitotoxicity-induced apoptosis in the hippocampus of mice lacking the Jnk3 gene. Nature 389:865-870.

Yu Z, Luo H, Fu W, Mattson MP (1999) The endoplasmic reticulum stressresponsive protein GRP78 protects neurons against excitotoxicity and apoptosis: suppression of oxidative stress and stabilization of calcium homeostasis. Exp Neurol 155:302-314.

Yuan J, Lipinski M, Degterev A (2003) Diversity in the mechanisms of neuronal cell death. Neuron 40:401-413.

Zafra F, Castren E, Thoenen H, Lindholm D (1991) Interplay between glutamate and gamma-aminobutyric acid transmitter systems in the physiological regulation of brain-derived neurotrophic factor and nerve growth factor synthesis in hippocampal neurons. Proc Natl Acad Sci USA 88:10037-10041. 